\title{
Controversy in the diagnosis and treatment of hemodynamically significant patent ductus arteriosus in preterm infants
}

Se In Sung, MD, PhD

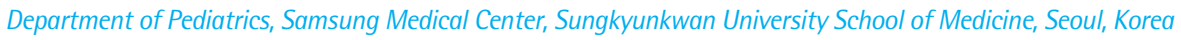

Lee ${ }^{1)}$ reported an excellent review article on the management of preterm patent ductus arteriosus (PDA) in a recent issue of the Korean Journal of Pediatrics. PDA in premature infants may be the most controversial topic in neonatology. The main reason for the controversy is the difficulty in detangling the consequences of hemodynamically significant (HS) PDA from that of prematurity per se because HS PDA is associated with both prematurity and poor neonatal morbidities. ${ }^{2)}$ Furthermore, although we reject the null hypothesis and agree to actively treat PDA to induce its closure, the current methodology and measures have limited ability to determine the hemodynamic significance of PDA and accordingly select high-risk patients who require pharmacological treatment or a more invasive surgical ligation with potentially detrimental effects. The clinical symptoms and signs of PDA are often obscure in extremely preterm infants, and the absence of classical physical signs does not exclude a large left-toright shunt. ${ }^{3)}$ The single index of ductal diameter measurement by echocardiography revealed a weak correlation with other various echocardiographic markers of shunt volume. ${ }^{4)}$ Therefore, as Lee mentioned, the combination of clinical and echocardiographic staging systems with or without biological markers, including NT-proB-type natriuretic peptide, is considered the best diagnostic tool to date for predicting the hemodynamic significance of PDA. ${ }^{5)}$ Moreover, near-infrared spectroscopy may be more desirable because it demonstrates the systemic impact of PDA rather than ductal characteristics. ${ }^{6}$ A recent study by Dagle et al. ${ }^{7}$ showed that single-nucleotide polymorphisms in several genes were associated with HS PDA that required surgical ligation, suggesting the genetic predisposition of HS PDA. Future studies to assess the hemodynamic significance of PDA through genetic, echocardiographic, and biologic tools will provide a more precise staging system for risk stratification.

The effect of active treatment for HS PDA is also controversial. Whether prolonged exposure to a moderate-to-large ductal shunt is detrimental and whether active treatment to reduce the duration of exposure to ductal shunt will decrease the incidence of neonatal morbidities remain to be determined. Well-designed randomized clinical trials will address these questions in the future. Since publication of the review article by Lee, the PDA-TOLERATE trial was published. ${ }^{8,9}$ The study included infants $<28$-week gestational age and compared the rates of surgical ligation, presence of PDA at hospital discharge, and various neonatal morbidities between the early routine and conservative treatment groups. In the study, early treatment did not reduce the frequency of PDA ligation or presence of PDA at discharge; however, it increased the incidence of sepsis and death in infants $\geq 26$-week gestation. However, the study has some limitations. Twenty-one percent of the eligible infants were not enrolled owing to unwillingness of the medical team. Sixty-three infants in the conservative treatment group eventually received rescue pharmacological treatment. Therefore, the study could be considered a comparison between early and late rescue treatments rather than between early and conservative treatments. The effect of active treatment compared with that of nonintervention
Corresponding author: Se In Sung, MD, PhD Department of Pediatrics, Samsung Medical Center, Sungkyunkwan University School of Medicine, 81 Irwon-ro, Gangnam-gu, Seoul 06351, Korea Tel: +82-2-3410-1775

Fax: +82-2-3410-0043

E-mail: sein.sung@samsung.com

https://orcid.org/0000-0002-8717-6142

Received: 22 May, 2019

Accepted: 17 June, 2019

See the article "Practice for preterm patent ductus arteriosus; focusing on the hemodynamic significance and the impact on the neonatal outcomes" in Volume 62 on page 245.

Copyright $(2019$ by The Korean Pediatric Society

This is an open-access article distributed under the terms of the Creative Commons Attribution NonCommercial License (http://creativecommons.org/ licenses/by-nc/4.0/) which permits unrestricted noncommercial use, distribution, and reproduction in any medium, provided the original work is properly cited. 
for preterm PDA may remain unclear. The wide variation among units in practice for HS PDA implies the urgency of establishing treatment guidelines for HS PDA in preterm infants.

\section{Conflicts of interest}

No potential conflict of interest relevant to this article was reported.

\section{References}

1. Lee JA. Practice for preterm patent ductus arteriosus; focusing on the hemodynamic significance and the impact on the neonatal outcomes. Korean J Pediatr 2019;62:245-51.

2. Bose CL, Laughon MM. Patent ductus arteriosus: lack of evidence for common treatments. Arch Dis Child Fetal Neonatal Ed 2007;92:F498502.
3. Skinner J. Diagnosis of patent ductus arteriosus. Semin Neonatol 2001;6:49-61.

4. de Freitas Martins F, Ibarra Rios D, F Resende MH, Javed H, Weisz D, Jain A, et al. Relationship of patent ductus arteriosus size to echocardiographic markers of shunt volume. J Pediatr 2018;202:50-55.e3.

5. El-Khuffash A, James AT, Corcoran JD, Dicker P, Franklin 0, Elsayed YN, et al. A patent ductus arteriosus severity score predicts chronic lung disease or death before discharge. J Pediatr 2015;167:1354-61. e2.

6. Chock VY, Rose LA, Mante JV, Punn R. Near-infrared spectroscopy for detection of a significant patent ductus arteriosus. Pediatr Res 2016;80:675-80.

7. Dagle JM, Ryckman KK, Spracklen CN, Momany AM, Cotten CM, Levy J, et al. Genetic variants associated with patent ductus arteriosus in extremely preterm infants. J Perinatol 2019;39:401-8.

8. Clyman RI, Liebowitz M, Kaempf J, Erdeve 0, Bulbul A, Håkansson S, et al. PDA-TOLERATE Trial: an exploratory randomized controlled trial of treatment of moderate-to-large patent ductus arteriosus at 1 week of age. J Pediatr 2019;205:41-8.e6.

9. Liebowitz M, Kaempf J, Erdeve O, Bulbul A, Håkansson S, Lindqvist J, et al. Comparative effectiveness of drugs used to constrict the patent ductus arteriosus: a secondary analysis of the PDA-TOLERATE trial (NCT01958320). J Perinatol 2019;39:599-607. 